\title{
Cardio-renal Correlations and Epicardial Adipose Tissue in Patients with Type 2 Diabetes
}

\author{
Simona Cernea ${ }^{1,2}$, Ciprian Blendea ${ }^{3}$, Andrada Larisa Roibann ${ }^{4}$ Theodora Benedek ${ }^{3}$ \\ 1 Department M3/Internal Medicine IV, University of Medicine and Pharmacy, Tîrgu Mureş, Romania \\ 2 Diabetes, Nutrition and Metabolic Diseases Outpatient Unit, County Emergency Clinical Hospital, Tîrgu Mureş, Romania \\ ${ }^{3}$ Clinic of Cardiology, University of Medicine and Pharmacy, Tîrgu Mureș, Romania \\ 4 Diabetes, Nutrition and Metabolic Diseases, County Emergency Clinical Hospital, Tîrgu Mureş, Romania
}

\section{CORRESPONDENCE}

\section{Simona Cernea}

Str. Gheorghe Marinescu nr. 38

540139 Tîrgu Mureş, Romania

Tel: +40 265215551

E-mail: simona.cernea@umftgm.ro

\section{ARTICLE HISTORY}

Received: November 16, 2017 Accepted: December 15, 2017
Ciprian Blendea • Str. Gheorghe Marinescu nr. 38 540139 Tîrgu Mureş, Romania. Tel: +40 265215551 Andrada Larisa Roiban - Str. Gheorghe Marinescu nr. 50, 540136 Tîrgu Mureș, Romania. Tel: +40 265212111 Theodora Benedek • Str. Gheorghe Marinescu nr. 38 540139 Tîrgu Mures, Romania. Tel: +40 265215551

\begin{abstract}
Aim: The aim of the study was to evaluate the correlation between renal function and heart function/echocardiographic parameters and epicardial adipose tissue thickness (EATT), respectively. Material and methods: Fifty patients with type 2 diabetes (T2D) were included in this study. Several laboratory parameters were obtained (HbA1c, fasting blood glucose, LDL-cholesterol, creatinine) and eGFR was calculated. Anthropometric measurements were performed (weight, waist and hip circumferences, 4 skinfolds, based on which \% body fat was calculated). Patients underwent echocardiographic assessment to evaluate structural and functional parameters, including EATT. Left ventricular mass (LVM) was calculated and the geometric changes of the left ventricle were evaluated. Results: Forty-six per cent of the patients had a LV ejection fraction (EF) $<55 \%$ and $34 \%$ had diastolic dysfunction. There were no significant differences between the three eGFR groups with regards to metabolic parameters, but LVEF was lower (53.0 $\pm 0.8 \%, 54.4 \pm 2.4 \%$, and $55.2 \pm 1.5 \%$, respectively) and EATT was higher (11.0 $\pm 1.0 \mathrm{~mm}, 8.58 \pm 2.2 \mathrm{~mm}$, and $7.63 \pm 2.6 \mathrm{~mm}$, respectively) with a lower eGFR $(p=0.04)$. More patients with eGFR $<90 \mathrm{~mL} / \mathrm{min} / 1.73 \mathrm{~m}^{2}$ had cardiac hypertrophy compared with those with eGFR $\geq 90 \mathrm{~mL} / \mathrm{min} / 1.73 \mathrm{~m}^{2}(p=0.04)$. EATT correlated positively with several anthropometric parameters, e.g. weight ( $r=0.309,95 \% \mathrm{Cl}$ : 0.022 to $0.549, p=0.03), \mathrm{BMI}(r=0.398$, 95\% Cl: 0.123 to $0.616, p=0.004)$, and negatively with LVEF ( $r=-0.496,95 \% \mathrm{Cl}:-0.687$ to $-0.242, p=0.0003)$ and eGFR ( $r=-0.293,95 \% \mathrm{Cl}:-0.531$ to $-0.013, p=0.04)$. In patients with LVEF $<55 \%$ vs. $\geq 55 \%$, the EATT was significantly higher $(9.5 \pm 1.99 \mathrm{~mm}$ vs. $7.33 \pm 2.37 \mathrm{~mm}$ $p=0.013)$. Conclusion: In patients with T2D decreased renal function was associated with lower LVEF and higher EATT. EATT was also higher in patients with reduced LVEF.
\end{abstract}

Keywords: type 2 diabetes, renal function, epicardial adipose tissue thickness, left ventricular ejection fraction, cardiac hypertrophy 


\section{INTRODUCTION}

The heart and the kidneys interact in a complex manner. There is a reciprocal link between heart failure (HF) and chronic kidney disease (CKD) that comprises common risk factors, bidirectional pathophysiological mechanisms, and mutual clinical consequences of one disease on the other. ${ }^{1}$ This interaction is aggravated when diabetes superimposes, and it complicates the progression and the therapeutic management of the diseases. ${ }^{1}$ Hyperglycemia/ glucotoxicity contributes through both direct and indirect mechanisms (e.g. oxidative stress, advanced glycation endproducts, inflammation etc.), which finally cause cellular injury and apoptosis. ${ }^{1-3}$

Altered fat distribution has emerged as an important factor associated with HF and CKD and is now the focus of considerable research. The epicardial adipose tissue (EAT) is a metabolically active visceral fat deposit surrounding the heart, associated with detrimental or cardioprotective effects. ${ }^{4}$ In patients with type 2 diabetes (T2D), EAT volume was shown to be higher and EAT thickness (EATT) to correlate with fasting glucose. ${ }^{5,6} \mathrm{~A}$ recent paper suggested that higher EAT volume is also associated with CKD, showing a good correlation between EAT and the estimated glomerular filtration rate (eGFR). ${ }^{7}$ In another study on the other hand, the EAT mass was shown to be reduced in patients with congestive HF and severely decreased left ventricular ejection fraction (LVEF). ${ }^{8}$ Although some patients had T2D, neither of the two studies reported separately the results encountered in this subgroup.

We conducted a preliminary study in patients with T2D aimed at evaluating the correlation between renal function and heart function/echocardiographic parameters and EATT, respectively.

\section{MATERIAL AND METHODS}

This was a cross-sectional study that included patients with T2D regularly seen in the Diabetes, Nutrition and Metabolic Diseases Outpatient Unit of the County Emergency Clinical Hospital of Tîrgu Mureş. The study was approved by the Ethics Committee of the County Emergency Clinical Hospital of Tîrgu Mureş and patients signed an informed consent before participating.

The subjects were included in the study if they were $\geq 18$ years old, had a previous diagnosis of $\mathrm{T} 2 \mathrm{D}$, and recently performed a small set of laboratory analysis during routine clinical visits. Exclusion criteria were type 1 diabetes, secondary diabetes, or gestational diabetes. Diagnosis of diabetes was established according to the American Diabetes Association criteria. ${ }^{9}$

The set of laboratory analysis included LDL cholesterol, HbA1c, and creatinine, with calculated eGFR. These were performed through a program developed throughout the country with the support of AstraZeneca Romania, aimed to evaluate the level of metabolic control in patients with diabetes. During regular visits to the clinic, patients were offered free coupons, based on which blood was drawn in an external laboratory in Tîrgu Mureş in a subsequent day. The HbA1c analysis was done by immunoturbidimetric method (Diabetes Control and Complications Trial [DCCT] standardized and National Glycohemoglobin Standardization Program [NGSP] certified). ${ }^{10}$ LDL cholesterol and serum creatinine were determined by enzymatic colorimetric methods. ${ }^{11,12}$ eGFR was estimated using the CKD-EPI (Chronic Kidney Disease Epidemiology Collaboration) equation and directly provided by the laboratory. ${ }^{13}$ The reason why the patients were selected from those having analysis done through the program was that all blood tests were performed in a single laboratory in a unitary manner, and thus inter-method variability was excluded.

After the laboratory results were received, patients were invited to participate in the study. Those who agreed to take part had their blood pressure (BP) measured in a subsequent day, along with several anthropometric measurements, performed by standard methods: weight (to the nearest $0.1 \mathrm{~kg}$ using a balance beam scale), waist and hip circumferences (by using an inelastic plastic tape), and 4 skinfolds: biceps, triceps, subscapular, and suprailiac (on the subject's right side, by using a lipocaliper). The $\mathrm{BP}$ and the skinfolds were measured twice, and the mean of the two measurements was calculated. Total body fat was calculated using the Durnin \& Womersley equation. ${ }^{14}$ Additional data were collected from the patients' medical records (last height measurement, mean fasting blood glucose [BG] at last visit, current therapy for diabetes, medical history). Body mass index (BMI) was calculated based on weight and height.

The echocardiographic assessment was done using a Vivid E90 equipment (General Electric Healthcare, Chicago, USA), by an independent cardiologist unaware of other aspects of the study. LVEF was evaluated using Simpson's rule, by dividing the stroke volume by the enddiastolic volume, after calculation of left ventricular (LV) end-diastolic and end-systolic volumes in apical 4 chamber view. Velocity time integral (VTI) at the level of the LV outflow tract (LVOT) was determined in apical 5 chamber view, using pulsed-wave Doppler technique with the Doppler sample placed at the level of the LVOT, followed by 
manual tracing of the Doppler curve recorded. LV diastolic function was assessed according to the recommendation of the ASE/ESC Guidelines for evaluation of diastolic dysfunction (DD), using conventional 2D echocardiography, pulsed-wave Doppler, and tissue Doppler imaging. ${ }^{15}$ Left atrial volume was calculated using $2 \mathrm{D}$ imaging, by measuring the mediolateral and supero-inferior diameters of the left atrium in apical 4 chamber view. Transmitral diastolic flow was assessed using pulsed-wave Doppler, in apical 4 chamber view. The following parameters were determined on the Doppler curve: maximum velocity of $\mathrm{E}$ wave, maximum velocity of A wave, and the E/A ratio. Tissue Doppler imaging was used for measuring the amplitude of $\mathrm{e}^{\prime}$ wave and for calculating the E/e' ratio. Systolic pressure in the pulmonary artery (PAP) was estimated using continuous wave Doppler, by adding the right atrial pressure (estimated at $10 \mathrm{~mm} \mathrm{Hg}$ ) to the pressure difference between the right ventricle and right atrium, which was calculated using the formula $\Delta \mathrm{P}=4 \mathrm{v}^{2}(\mathrm{v}=$ maximum velocity of the regurgitating tricuspid flow). EATT was measured in parasternal long axis view (one measurement was missing).

Left ventricular mass (LVM) was thereafter calculated using the following validated formula recommended by the European Association of Cardiovascular Imaging $(\mathrm{EACVI}) / \mathrm{ASE}: \mathrm{LVM}=0.80\left[1.04 \times(\mathrm{PW}+\mathrm{VS}+\mathrm{LVDd})^{3}\right.$ $\left.-(\mathrm{LVDd})^{3}\right]+0.6(\mathrm{PW}$ : posterior wall diastole; VS: interventricular septum diastole, LVDd: LV internal dimension diastole). ${ }^{16}$ The LVM index (LVMi) was calculated as the LVM divided by the body surface area. ${ }^{16}$ The geometric changes of the LV were evaluated based on LVMi and relative wall thickness (RWT). A RWT $\leq 0.42$, a LVMi (male) $<115 \mathrm{~g} / \mathrm{m}^{2}$, and a LVMi (female) $<95 \mathrm{~g} / \mathrm{m}^{2}$ were regarded as normal. Four different categories were defined: concentric hypertrophy (increased RWT with increased LVMi), concentric remodeling (increased RWT with normal LVMi), eccentric remodeling (normal RWT with increased LVMi), and normal geometry (normal RWT and normal LVMi). ${ }^{16}$

Descriptive statistics was performed for all variables and expressed as mean ( $\pm \mathrm{SD}$ ) or median (min-max) for continuous variables with normal or non-normal distribution, respectively, and frequency (\%) for categorical variables. Normality of data was tested using the KolmogorovSmirnov test. Student's $t$ test, the Mann-Whitney test, ANOVA, and the Kruskal-Wallis test were employed, respectively, to compare means and medians between groups. Fisher's exact test was used for analysis of categorical variables. Spearman's and Pearson's correlation coefficients were calculated to evaluate the relationship between the variables of interest. Multiple regression analysis was done to evaluate the impact of EATT on renal function. All test were two-tailed, and the statistical significance was set at $\mathrm{p}<0.05$. Statistical analysis was performed using GraphPad InStat 3 (GraphPad Software, Inc., San Diego, CA, USA).

\section{RESULTS}

From 82 patients who had laboratory analysis performed through the program between October and December 2016, we have evaluated 50 patients with T2D in this study. Main demographic characteristics and medical data are shown in Table 1. There was an equal gender proportion (male/ female $=25 / 25$ ), and the mean age was $64.7 \pm 8.8$ years in this group. With regards to specific therapy for T2D, 2/50 patients (4\%) were on diet alone, 27/50 patients (54\%) were on monotherapy with metformin, 7/50 patients (14\%) were on dual therapy (with metformin plus a sulphonyurea or a dipeptidyl peptidase 4 inhibitor), 6/50 patients $(12 \%)$ were on triple therapy with oral/injectable antihyperglycemic agents, and 8/50 patients (16\%) were on insulin therapy (with/without metformin).

TABLE 1. Demographic and medical characteristics of study patients

\begin{tabular}{lc}
\hline Characteristics & \\
\hline Gender (M/F) (no) & $25 / 25$ \\
Age (years) & $64.7 \pm 8.8$ \\
Diabetes duration (years) & $5.0(0.5-26)$ \\
Systolic BP (mmHg) & $131.5 \pm 14.7$ \\
Diastolic BP (mmHg) & $79.5 \pm 10.3$ \\
History of hypertension (no/\%) & $46 / 88$ \\
History of Ml (no/\%) & $2 / 4$ \\
History of ischemic heart disease (no/\%) & $28 / 56$ \\
History of stroke (no/\%) & $6 / 12$ \\
History of peripheral arterial disease (no/\%) & $7 / 14$ \\
Smoking status & \\
$\quad$ Current (no/\%) & $12 / 24$ \\
Former (no/\%) & $19 / 38$ \\
$\quad$ Never (no/\%) & $19 / 38$ \\
Fasting blood glucose (mg/dL) & $122.4 \pm 18.1$ \\
HbA1c (\%) & $6.6 \pm 0.9$ \\
LDL cholesterol (mg/dL) & $119.5 \pm 36.6$ \\
Creatinine (mg/dL) & $0.8 \pm 0.2$ \\
eGFR (mL/min/1.73 m²) & $84.7 \pm 15.5$ \\
Patients with eGFR: & \\
$\geq 90$ mL/min/1.73 m² (no) & 22 \\
$60-89$ mL/min/1.73 m² (no) & 24 \\
$30-59$ mL/min/1.73 m² (no) & 4 \\
15-29 mL/min/1.73 m² (no) & 0 \\
$<15$ mL/min/1.73 m² (no) & 0 \\
\hline
\end{tabular}


TABLE 2. Anthropometric characteristics of $T 2 D$ patients included in the study

\begin{tabular}{lcccc}
\hline Anthropometric data & All & $\mathbf{M}(\mathbf{n}=\mathbf{2 5})$ & $\mathbf{F ~ ( n = ~ 2 5 )}$ & $\mathbf{p}$ \\
\hline Weight $(\mathrm{kg})$ & $85.0(51.5-150.5)$ & $91.5(54.5-150.5)$ & $77.4 \pm 11.2$ & 0.0012 \\
BMI $\left(\mathrm{kg} / \mathrm{m}^{2}\right)$ & $30.6(20.8-47.5)$ & $30.0(20.8-47.5)$ & $31.6 \pm 3.7$ & NS \\
Waist circumference $(\mathrm{cm})$ & $106.9 \pm 11.0$ & $110.3 \pm 11.6$ & $103.5 \pm 9.5$ & 0.028 \\
Hip circumference $(\mathrm{cm})$ & $107.6 \pm 10.1$ & $107.4 \pm 11.7$ & $107.7 \pm 8.4$ & $\mathrm{NS}$ \\
Waist to hip ratio $(\mathrm{WHR})$ & $0.99 \pm 0.06$ & $1.03 \pm 0.04$ & $0.96 \pm 0.06$ & $<0.0001$ \\
Biceps skinfold (mm) & $17.1 \pm 6.3$ & $14.2 \pm 6.7$ & $20.0 \pm 4.4$ & 0.0009 \\
Triceps skinfold $(\mathrm{mm})$ & $21.2 \pm 8.0$ & $17.1 \pm 9.0$ & $25.3 \pm 3.7$ & 0.0002 \\
Subscapular skinfold $(\mathrm{mm})$ & $29.4 \pm 7.6$ & $27.7 \pm 8.1$ & $30.9 \pm 6.7$ & $\mathrm{NS}$ \\
Suprailiac skinfold $(\mathrm{mm})$ & $22.3 \pm 7.2$ & $21.7 \pm 8.9$ & $22.9 \pm 4.9$ & $\mathrm{NS}$ \\
Total body fat (\%) & $40.7(25.3-45.7)$ & $32.1(25.2-44.7)$ & $42.1(36.0-45.7)$ & $<0.0001$ \\
\hline
\end{tabular}

The anthropometric parameters of study participants are summarized in Table 2. Female subjects had higher biceps and triceps skinfolds and higher \% calculated total body fat, although there was no significant difference between their BMIs (Table 2).

Since the only renal evaluation was eGFR, we could not actually stage CKD. However, $8 \%$ of patients had an eGFR $<60 \mathrm{~mL} / \mathrm{min} / 1.73 \mathrm{~m}^{2}$ (mean eGFR: $51.2 \pm 5.1 \mathrm{~mL} /$ $\left.\mathrm{min} / 1.73 \mathrm{~m}^{2}\right), 48 \%$ had an eGFR of $60-89 \mathrm{~mL} / \mathrm{min} / 1.73 \mathrm{~m}^{2}$ (mean eGFR: $77.9 \pm 7.7 \mathrm{~mL} / \mathrm{min} / 1.73 \mathrm{~m}^{2}$ ), and $44 \%$ had an eGFR $>60 \mathrm{~mL} / \mathrm{min} / 1.73 \mathrm{~m}^{2}$ (mean eGFR: $98.1 \pm 5.8$ $\mathrm{mL} / \mathrm{min} / 1.73 \mathrm{~m}^{2}$ ). There were no significant differences between the three groups with regards to glycemic control (fasting BG: $118 \pm 10.8 \mathrm{mg} / \mathrm{dL}$ vs. $120 \pm 17.8 \mathrm{mg} / \mathrm{dL}$ vs. $125.9 \pm 19.5 \mathrm{mg} / \mathrm{dL}$, and HbA1c: $6.6 \pm 0.8 \%$ vs. $6.5 \pm 0.8 \%$ vs. $6.8 \pm 1 \%$, respectively) or LDL cholesterol levels $(102.2 \pm 17.5 \mathrm{mg} / \mathrm{dL}$ vs. $129.3 \pm 37.0 \mathrm{mg} / \mathrm{dL}$ vs. $111.9 \pm$ $36.8 \mathrm{mg} / \mathrm{dL}$, respectively) ( $\mathrm{p}>0.05$ for all).

TABLE 3. Main echocardiographic structural and functional parameters in subjects with T2D

\begin{tabular}{|c|c|c|c|c|}
\hline $\begin{array}{l}\text { Echocardiographic } \\
\text { parameters }\end{array}$ & $\begin{array}{c}\text { eGFR }<60 \mathrm{~mL} / \mathrm{min} / 1.73 \mathrm{~m}^{2} \\
\text { (group 1) }\end{array}$ & $\begin{array}{c}\text { eGFR: } 60-89 \mathrm{~mL} / \mathrm{min} / 1.73 \mathrm{~m}^{2} \\
\text { (group 2) }\end{array}$ & $\begin{array}{c}\text { eGFR } \geq 90 \mathrm{~mL} / \mathrm{min} / 1.73 \mathrm{~m}^{2} \\
\text { (group 3) }\end{array}$ & $p$ \\
\hline \multicolumn{5}{|l|}{ Structural parameters } \\
\hline LVMi $\left(g / \mathrm{m}^{2}\right)$ & $108.3 \pm 11.8$ & $120.5 \pm 20.4$ & $123.4 \pm 22.3$ & NS \\
\hline $\operatorname{LVM}(g)$ & $198.5 \pm 38.5$ & $225.1 \pm 34.7$ & $242.6 \pm 52.3$ & NS \\
\hline Septum (mm) & $12.5 \pm 1.3$ & $12.4 \pm 1.3$ & $12.9 \pm 1.7$ & NS \\
\hline Posterior wall (mm) & $10.0 \pm 1.2$ & $10.5 \pm 1.0$ & $11.1 \pm 1.3$ & NS \\
\hline LAD transversal (mm) & $40.5 \pm 2.6$ & $36.3 \pm 6.2$ & $37.7 \pm 6.5$ & NS \\
\hline LAD lateral (mm) & $55.7 \pm 4.0$ & $53.6 \pm 5.8$ & $55.7 \pm 7.0$ & NS \\
\hline LV end-diastolic volume (ml) & $88.5 \pm 14.3$ & $100.8 \pm 16.4$ & $97 \pm 19.5$ & NS \\
\hline LV end-systolic volume (ml) & $35.2 \pm 10.9$ & $45.9 \pm 11.3$ & $44.2 \pm 12.6$ & NS \\
\hline $\mathrm{Ao}(\mathrm{mm})$ & $30.5 \pm 3.4$ & $33.9 \pm 3.9$ & $31.8 \pm 2.8$ & NS \\
\hline $\mathrm{RWT}(\mathrm{mm})$ & $0.42 \pm 0.04$ & $0.42 \pm 0.05$ & $0.44 \pm 0.05$ & NS \\
\hline $\operatorname{EATT}(\mathrm{mm})$ & $11.0 \pm 1.0$ & $8.58 \pm 2.2$ & $7.63 \pm 2.6$ & 0.04 \\
\hline \multicolumn{5}{|l|}{ Functional parameters } \\
\hline LVEF (\%) & $53.0 \pm 0.8$ & $54.4 \pm 2.4$ & $55.2 \pm 1.5$ & 0.04 \\
\hline$E / A$ & $1.2 \pm 0.43$ & $0.92 \pm 0.36$ & $1.06 \pm 0.41$ & NS \\
\hline DcT (msec) & $222.5 \pm 25.7$ & $204.0 \pm 30.2$ & $207.9 \pm 22.4$ & NS \\
\hline e' lateral (cm/sec) & $13.2 \pm 1.2$ & $15.4 \pm 2.7$ & $14.3 \pm 2.7$ & NS \\
\hline e' septal (cm/sec) & $9.7 \pm 1.5$ & $11.0 \pm 3.0$ & $9.7 \pm 3.3$ & NS \\
\hline PAP $(\mathrm{mmHg})$ & $20.5 \pm 8.3$ & $22.5 \pm 9.8$ & $17.6 \pm 8.5$ & NS \\
\hline \multicolumn{5}{|l|}{ Parameters of $L V$ preload } \\
\hline E/e' lateral & $7.1 \pm 3.2$ & $5.9 \pm 1.7$ & $6.6 \pm 2.0$ & NS \\
\hline E/e' septal & $9.7 \pm 1.5$ & $11.0 \pm 3.0$ & $9.7 \pm 3.3$ & NS \\
\hline
\end{tabular}




\section{Echocardiographic structural and functional parameters}

In the study group, $23(46 \%)$ patients had LVEF $<55 \%$ (2 of them had LVEF <50\%), and 17 (34\%) had DD as determined by the cardiologist, according to previously defined criteria. ${ }^{15}$ The main echocardiographic parameters according to eGFR stages are presented in Table 3.

When cardiac geometry changes were evaluated, 20 out of 50 (40\%) patients had cardiac hypertrophy, 19 (38\%) had eccentric hypertrophy, 3 (6\%) had cardiac remodeling, and only $8(16 \%)$ had normal cardiac geometry. In patients with or without cardiac (concentric and eccentric) hypertrophy, respectively, there were no statistically significant differences between anthropometric parameters such as BMI $\left(32.0 \pm 5.29 \mathrm{~kg} / \mathrm{m} 2\right.$ vs. $29.9 \pm 3.97 \mathrm{~kg} / \mathrm{m}^{2}$, $\mathrm{p}>0.05)$, waist circumference $(107.6 \pm 11.5 \mathrm{~cm}$ vs. $104.7 \pm$ $9.6 \mathrm{~cm}, \mathrm{p}>0.05)$, total body fat $(38.2 \pm 6.2 \%$ vs. $35.6 \pm 5.8 \%$, p >0.05), or metabolic parameters (HbAlc: $6.52 \pm 0.69 \%$ vs. $6.99 \pm 1.25 \%$, LDL cholesterol: $120.2 \pm 36.6 \mathrm{mg} / \mathrm{dL}$ vs. $117.1 \pm 37.8 \mathrm{mg} / \mathrm{dL}, \mathrm{p}>0.05$ for both). However, T2D patients with cardiac hypertrophy were significantly older (66.4 \pm 7.7 years vs. $58.0 \pm 9.2$ years, $p=0.003)$.

LVM correlated with body weight $(\mathrm{r}=0.356,95 \% \mathrm{CI}$ : 0.075 to $0.585, \mathrm{p}=0.01)$ and waist circumference $(\mathrm{r}=0.359$, $95 \%$ CI: 0.090 to $0.579, \mathrm{p}=0.01)$, but not with BMI or total body fat, while LVMi did not correlate with any anthropometric parameters.

\section{Renal function}

In this study group, the eGFR correlated negatively with age $(\mathrm{r}=-0.656,95 \% \mathrm{CI}:-0.790$ to $-0.462 ; \mathrm{p}<0.0001)$ and positively with diastolic BP $(\mathrm{r}=0.319,95 \% \mathrm{CI}: 0.036$ to $0.555, p=0.02)$, diastolic LV diameter $(r=0.303,95 \% \mathrm{CI}$ : 0.018 to $0.542, \mathrm{p}=0.03)$, right ventricle diameter $(\mathrm{r}=0.283$, 95\% CI: 0.005 to $0.520, p=0.04), \operatorname{LVM}(r=0.304,95 \%$ CI: 0.028 to $0.537, \mathrm{p}=0.031$ ), but the correlation with LVMi was not significant ( $\mathrm{r}=0.208,95 \% \mathrm{CI}$ : -0.082 to 0.467 , $\mathrm{p}>0.05$ ). However, the eGFR did not correlate with diabetes duration, metabolic parameters (HbA1c, LDL cholesterol, BG), other ultrasound measurements (although there was a borderline negative correlation with PAPs $\mathrm{r}=-0.278,95 \% \mathrm{CI}:-0.522$ to $0.008, \mathrm{p}=0.0506$ ) or anthropometric measurements (body weight, BMI, total body fat, waist or hip circumferences, $\mathrm{p}>0.05$ for all).

There was no significant difference in eGFR values between patients with or without DD $(85.3 \pm 12.6$ vs. $84.4 \pm$ $16.9, \mathrm{p}>0.05)$. However, the LVEF was significantly lower with decreasing eGFR categories (Table 3).
TABLE 4. eGFR categories and presence of cardiac hypertrophic changes in patients with $\mathrm{T} 2 \mathrm{D}$

\begin{tabular}{lcc}
\hline eGFR category & $\begin{array}{c}\text { No cardiac } \\
\text { hypertrophy } \\
\text { (no) }\end{array}$ & $\begin{array}{c}\text { Cardiac } \\
\text { hypertrophy } \\
\text { (no) }\end{array}$ \\
\hline$<90 \mathrm{~mL} / \mathrm{min} / 1.73 \mathrm{~m}^{2}$ & 3 & 25 \\
$\geq 90 \mathrm{~mL} / \mathrm{min} / 1.73 \mathrm{~m}^{2}$ & 8 & 14 \\
\hline
\end{tabular}

Changes in cardiac geometry were further analyzed according to eGFR. Due to the small number of subjects in the lower eGFR category, we decided to evaluate the presence/absence of cardiac hypertrophy in patients with eGFR $>$ or $<90 \mathrm{~mL} / \mathrm{min} / 1.73 \mathrm{~m}^{2}$ and found that more patients with eGFR $<90 \mathrm{~mL} / \mathrm{min} / 1.73 \mathrm{~m}^{2}$ had cardiac hypertrophy $(p=0.04)($ Table 4$)$.

\section{Epicardial fat thickness}

The EATT was analyzed in relation with anthropometric measurements, and we found that in our study population EATT correlated positively with weight $(\mathrm{r}=0.309$, 95\% CI: 0.022 to $0.549, \mathrm{p}=0.03)$, BMI $(\mathrm{r}=0.398,95 \% \mathrm{CI}$ : 0.123 to $0.616, p=0.004), \%$ body fat $(r=0.338,95 \% \mathrm{CI}$ : 0.054 to $0.571, \mathrm{p}=0.01)$, waist circumference $(\mathrm{r}=0.314$, 95\% CI: 0.036 to $0.547, \mathrm{p}=0.02)$, but not hip circumference or waist to hip ratio $(\mathrm{p}>0.05)$. In addition, EATT positively correlated with biceps skinfold $(r=0.298,95 \%$ CI: 0.018 to $0.534, \mathrm{p}=0.037)$, triceps skinfold $(\mathrm{r}=0.413$, 95\% CI: 0.149 to $0.622, \mathrm{p}=0.003)$, subscapular skinfold $(\mathrm{r}=0.350,95 \%$ CI: 0.076 to $0.574, \mathrm{p}=0.013)$, and suprailiac skinfold ( $\mathrm{r}=0.389,95 \% \mathrm{CI}: 0.121$ to $0.604, \mathrm{p}=0.005$ ).

There was no significant correlation between EATT and metabolic parameters (HbAlc, fasting BG, or LDLcholesterol) ( $\mathrm{p}>0.05$ for all). EATT did not significantly differ between the T2D patients with or without DD $(8.94 \pm 2.01 \mathrm{~mm}$ vs. $7.96 \pm 2.0 \mathrm{~mm}, \mathrm{p}>0.05)$ or between patients with or without cardiac (concentric and eccentric) hypertrophy ( $8.39 \pm 2.18 \mathrm{~mm}$ vs. $8.0 \pm 3.28 \mathrm{~mm}, \mathrm{p}>0.05)$. However, the EATT negatively correlated with LVEF ( $\mathrm{r}=-0.496,95 \% \mathrm{CI}:-0.687$ to $-0.242, \mathrm{p}=0.0003)$. In patients with LVEF $<55 \%$, the EATT was significantly higher $(9.5 \pm 1.99 \mathrm{~mm})$ than in those with LVEF $\geq 55 \%$ (7.33 \pm $2.37 \mathrm{~mm})(\mathrm{p}=0.013)$.

We further analyzed the EATT correlation with renal function and found that it negatively correlated with eGFR ( $r=-0.293,95 \% \mathrm{CI}:-0.531$ to $-0.013, \mathrm{p}=0.04$ ). Moreover, the eGFR correlated to EATT indexed to BMI $(\mathrm{r}=-0.299,95 \% \mathrm{CI}:-0.535$ to $-0.019, \mathrm{p}=0.03)$ and EATT to body weight $(r=-0.319,95 \% \mathrm{CI}:-0.551$ to -0.042 , 

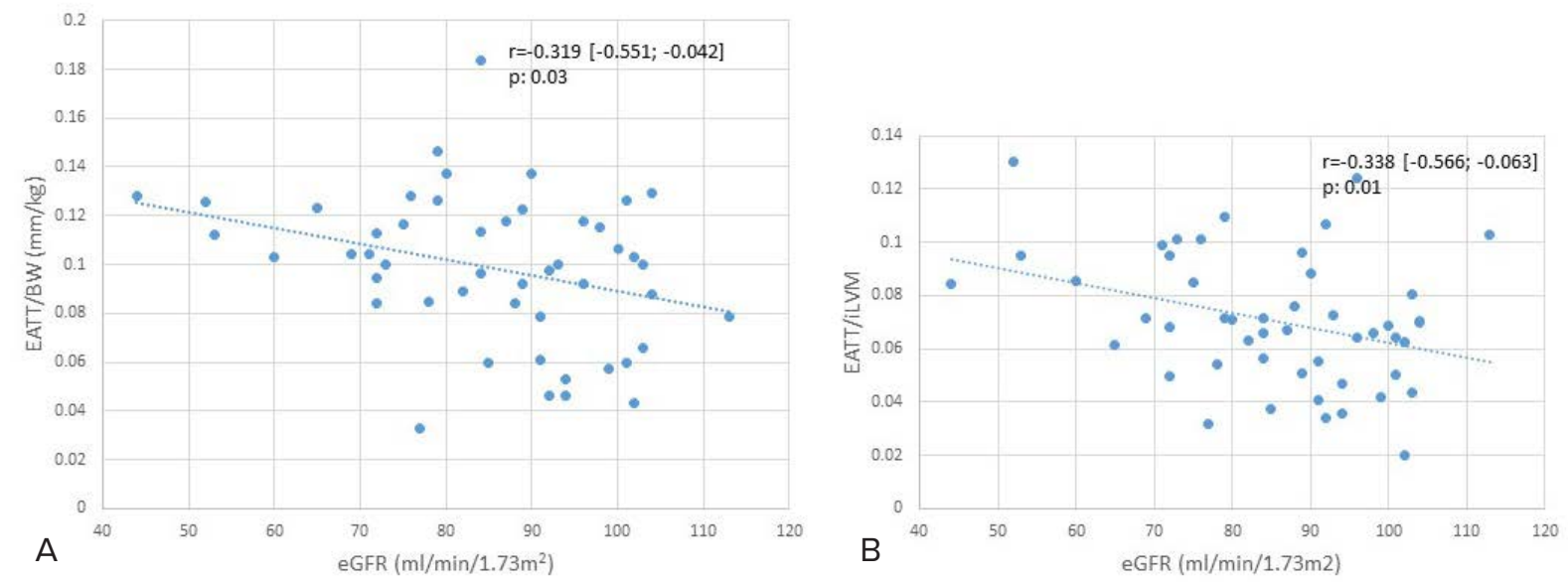

FIGURE 1. Correlation between A - eGFR and EATT indexed to body weight and $\mathbf{B}$ - eGFR and EATT indexed to LVMi in patients with $T 2 D$

$\mathrm{p}=0.02$ ) (Figure 1A), but also with EATT indexed to LVM $(\mathrm{r}=-0.408,95 \% \mathrm{CI}:-0.618$ to $-0.143, \mathrm{p}=0.003)$ and to LVMi ( $\mathrm{r}=-0.338,95 \% \mathrm{CI}:-0.566$ to $-0.063, \mathrm{p}=0.01)$ (Figure 1B).

On multivariate analysis, the correlation of EATT with eGFR remained significant when eGFR, BG, HbAlc, LDL cholesterol, LVM, and BMI were used as variables ( $\mathrm{p}=$ 0.003) (eGFR: $-0.048,95 \%$ CI: -0.090 to $-0.006, \mathrm{p}=0.02$; BG: $-0.047,95 \% \mathrm{CI}:-0.088$ to $-0.006, \mathrm{p}=0.02$; and $\mathrm{BMI}$ : $0.231,95 \%$ CI: 0.103 to $0.360, p=0.0007$ had a significant contribution on EATT).

\section{DISCUSSION}

This was a preliminary study conducted in patients with T2D in whom we evaluated the eGFR and several echocardiographic parameters, including EATT, in order to assess the cardio-renal correlation in this group. Firstly, our data showed that one third of patients with T2D with a relatively short duration of diabetes (median 5 years) had diastolic dysfunction, and a high proportion of patients had an $\mathrm{EF}<55 \%$. A previous study in $605 \mathrm{~T} 2 \mathrm{D}$ patients older than 60 years and with a similar duration of diabetes (median 5.5 [3.0 to 15.2]) reported similar results $(25.1 \%)^{17}$ An earlier study reported a prevalence of $47 \%$ of diastolic dysfunction in 289 patients with T2D. ${ }^{18}$ Diastolic dysfunction is considered an early manifestation of diabetic cardiomyopathy and given its high prevalence in patients with T2D, quite early in the disease course, perhaps a more structured screening program would be advisable for them. ${ }^{19}$

Additionally, about three quarters of the evaluated T2D patients presented changes in cardiac geometry, mostly concentric and eccentric hypertrophy. A study in a T2D population of different ethnicity indicated a higher percentage of T2D patients with normal cardiac geometry (49.2\%). ${ }^{20}$ However, these subjects were younger (mean age $55.0 \pm 8.5$ years), and age is a factor influencing changes in cardiac geometry, as observed in our data as well. A more recent study in 353 Caucasian patients with/without obesity, hypertension and T2D demonstrated that the percentage of T2D with normal cardiac geometry varies according to the presence of the two comorbidities ( $52 \%$ in normotensive T2D, $29 \%$ in hypertensive T2D, $20 \%$ in normotensive obese T2D, and $4 \%$ in hypertensive obese T2D). ${ }^{21}$

Renal function, as evaluated by eGFR, did not differ in patients with or without diastolic dysfunction. In contrast, eGFR correlated with LVM, and we noticed that lower eGFR was associated with hypertrophic changes in T2D hearts. However, the low number of patients included in the study did not allow definite conclusions to be drawn, and certainly more investigation is needed. A Japanese study in 309 patients with cardiovascular risk factors (of whom $28 \%$ had diabetes) indicated that $\mathrm{LV}$ hypertrophy predicts low eGFR better than diastolic dysfunction by using echocardiography. ${ }^{22}$ In our study, only DBP correlated with eGFR, while the other cardiovascular risk factors did not. Hypertension is acknowledged as a strong risk factor for both heart and renal dysfunction. Somewhat surprising was the lack of correlation of eGFR with parameters of glycemic control, but this could be explained perhaps by the number of patients included and the fact that diabetes was well controlled in this group - mean HbAlc was $6.6 \%$, and most patients reached the glycemic targets. 
An important finding of this preliminary study was that eGFR correlated negatively with EATT in patients with T2D. This correlation remained significant even after EATT was indexed to body fat and LVM. It has become apparent that ectopic (epicardial) fat accumulation contributes to cardiovascular disease/HF and CKD. This could be explained by the fact that the visceral adipose tissue depot around the heart is metabolically active and can influence cardiac function/homeostasis, partly through metabolic (e.g. hyperglycemia/insulin resistance, fatty acid overload with increased $\beta$ oxidation and OS), endocrine/paracrine, and inflammatory pathways. ${ }^{4,23}$ This could also be true for CKD, as our data, as well as data from another recent paper in patients with/without CKD, indicated correlation between EAT accumulation and eGFR ( $\mathrm{r}=-0.34, \mathrm{p}<0.01) .^{7}$ Additional putative factors/ pathological mechanisms suggested to correlate EAT with heart disease and/or CKD were microangiopathy/endothelial dysfunction, pro-atherogenic mediators, and adipokines (increased leptin, resistin, decreased adiponectin). ${ }^{24-26}$ Mainly leptin and adiponectin were suggested to play a role in both heart and kidney pathophysiology, although the exact mechanisms and if they may represent the link between HF and CKD in T2D patients is not entirely elucidated. ${ }^{27-29}$

It is interesting to notice that only epicardial fat accumulation was negatively correlated with eGFR, while total body fat was not. The correlation of eGFR with EATT was seen despite the fact that eGFR did not correlate with any anthropometric parameters. This could suggest that some factors predominantly secreted in the EAT may be more deleterious for renal function. Also, EATT correlated with waist circumference, BMI, and all four upperbody skinfolds, but not hip circumference, which might suggest that EAT accumulates in concordance with fat accumulation in the upper part of the body. On the other hand, studies have shown that weight loss is associated with reduction of EAT, suggesting that ectopic fat accumulation is modifiable. ${ }^{30}$ However, its impact on heart function in T2D patients with kidney dysfunction has not been evaluated.

In contrast to previous reports, our data indicated that EATT was higher in patients with reduced EF. In patients with congestive HF, due to ischemic or dilated cardiomyopathy and with severely reduced EF $(<35 \%)$, indexed EAT mass was found to be reduced. ${ }^{8}$ However, EATT has been shown to increase in patients with ischemic heart disease, as a marker of augmented inflammation in coronary artery disease. ${ }^{4,31}$ Similarly, in our study on T2D patients, including a significant proportion of cases with a history of coronary artery disease, EATT was significantly associated with a reduction in $\mathrm{EF}$, showing that in diseases associated with an expressed inflammation, increased EATT is associated with alteration of ventricular function. Another recent study performed in metabolically healthy morbidly obese subjects has also reported a negative correlation between LVEF and EATT. 32

\section{Study limitations}

There are several limitations to our study, the most important being the low number of patients, mainly in the low eGFR category, which precluded the evaluation of concentric or eccentric cardiac hypertrophy according to eGFR category. Secondly, due to lack of albuminuria data, renal function was not completely evaluated, thus LV changes could not be fully assessed in relation to CKD stages. And finally, EAT was evaluated by measuring its thickness by ultrasound, and nowadays the gold standard is represented by the assessment of EAT volume by computed tomography. However, we consider that these data are relevant and represent a consistent basis for further development of research in this direction.

\section{CONCLUSIONS}

In patients with $\mathrm{T} 2 \mathrm{D}$, decreased renal function was associated with lower LVEF and higher EATT. Diabetic patients with reduced EF showed higher values of EATT as compared to those with normal EF, indicating that an increased EATT can serve as a risk marker for both renal injury and deterioration of ventricular function in patients with T2D.

\section{ACKNOWLEDGEMENT}

The laboratory tests were performed independently through a national program supported by AstraZeneca Romania.

\section{CONFLICTS OF INTEREST}

SC received payment for lectures from AstraZeneca, Berlin-Chemie Menarini, Eli Lilly, Novo Nordisk, Sanofi, Servier Pharma, for clinical trial Steering Committee meetings as National Lead Investigator for DECLARE-TIMI58 from the TIMI Study Group, and support for travel to meetings from AstraZeneca, Eli Lilly, Sanofi, MSD. CB and ALR declare no conflict of interest. TB received payment for lectures from AstraZeneca, Sanofi, Pfizer, Bayer. 


\section{REFERENCES}

1. Cernea S. Heart failure and chronic kidney disease in type 2 diabetes. Journal of Interdisciplinary Medicine. 2016;1:252-258.

2. Battiprolu PK, Gillette TG, Wang ZV, et al. Diabetic Cardiomyopathy: Mechanisms and Therapeutic Targets. Drug Discov Today Dis Mech. 2010;7:e135-e143.

3. McMurray JJ, Gerstein HC, Holman RR, et al. Heart failure: a cardiovascular outcome in diabetes that can no longer be ignored. Lancet Diabetes Endocrinol. 2014;2:843-851.

4. Matloch Z, Kotulák T, Haluzík M. The role of epicardial adipose tissue in heart disease. Physiol Res. 2016;65:23-32.

5. Wang CP, Hsu HL, Hung WC, et al. Increased epicardial adipose tissue (EAT) volume in type 2 diabetes mellitus and association with metabolic syndrome and severity of coronary atherosclerosis. Clin Endocrinol (Oxf). 2009;70:876-882.

6. lacobellis G, Barbaro G, Gerstein HC. Relationship of epicardial fat thickness and fasting glucose. Int J Cardiol. 2008;128:424-426.

7. Nakanishi K, Fukuda S, Tanaka A, et al. Epicardial Adipose Tissue Accumulation Is Associated With Renal Dysfunction and Coronary Plaque Morphology on Multidetector Computed Tomography. Circ J. 2016;80:196201.

8. Doesch C, Haghi D, Flüchter S, et al. Epicardial adipose tissue in patients with heart failure. J Cardiovasc Magn Reson. 2010;12:40

9. American Diabetes Association. Standards of Medical Care in Diabetes-2017. Diabetes Care. 2017;40(Suppl 1):S1-S135

10. Laborator Synevo. Referintele specifice tehnologiei de lucru utilizate. Available at: https://www.synevo.ro/hemoglobina-glicata-hb-a1c/

11. Laborator Synevo. Referintele specifice tehnologiei de lucru utilizate. Available at: https://www.synevo.ro/colesterol-ldl/

12. Laborator Synevo. Referintele specifice tehnologiei de lucru utilizate. Available at: https://www.synevo.ro/creatinina-serica/

13. Levey AS, Stevens LA, Schmid CH, et al. CKD-EPI (Chronic Kidney Disease Epidemiology Collaboration). A New Equation to Estimate Glomerular Filtration Rate. Ann Intern Med. 2009;150:604-612.

14. Durnin J, Womersley J. Body fat assessed from total body density and its estimation from skinfold thickness: measurements on 481 men and women aged from 16 to 72 years. Br J Nutr. 1974;32:77-97.

15. Nagueh SF, Smiseth OA, Appleton CP, et al. ASE/EACVI GUIDELINES AND STANDARDS. Recommendations for the Evaluation of Left Ventricular Diastolic Function by Echocardiography: An Update from the American Society of Echocardiography and the European Association of Cardiovascular Imaging. Eur Heart J Cardiovasc Imaging. 2016;17:13211360 .

16. Marwick TH, Gillebert TC, Aurigemma G, et al. Recommendations on the use of echocardiography in adult hypertension: a report from the European Association of Cardiovascular Imaging (EACVI) and the American Society of Echocardiography (ASE). Eur Heart J Cardiovasc Imaging. 2015;16:577605.
17. Boonman-de Winter LJ, Rutten FH, Cramer MJ, et al. High prevalence of previously unknown heart failure and left ventricular dysfunction in patients with type 2 diabetes. Diabetologia. 2012;55:2154-2162.

18. Henry RM, Paulus WJ, Kamp O, et al. Deteriorating glucose tolerance status is associated with left ventricular dysfunction--the Hoorn Study. Neth J Med. 2008;66:110-117.

19. Boudina S, Abel ED. Diabetic cardiomyopathy revisited. Circulation. 2007:115:3213-3223

20. Ojji DB, Adebiyi AA, Oladapo OO, et al. Left ventricular geometric patterns in normotensive type 2 diabetic patients in Nigeria: an echocardiographic study. Prev Cardiol. 2009;12:184-188

21. De Jong KA, Czeczor JK, Sithara S, et al. Obesity and type 2 diabetes have additive effects on left ventricular remodelling in normotensive patients-a cross sectional study. Cardiovasc Diabetol. 2017;16:21.

22. Masugata H, Senda S, Goda F, et al. Echocardiographic assessment of the cardio-renal connection: is left ventricular hypertrophy or diastolic function more closely correlated with estimated glomerular filtration rate in patients with cardiovascular risk factors? Clin Exp Hypertens. 2010;32:113-120.

23. Salazar J, Luzardo E, Mejías JC, et al. Epicardial Fat: Physiological, Pathological, and Therapeutic Implications. Cardiol Res Pract. 2016;2016:1291537.

24. Parisi V, Rengo G, Pagano G, et al. Epicardial adipose tissue has an increased thickness and is a source of inflammatory mediators in patients with calcific aortic stenosis. Int J Cardiol. 2015;186:167-169.

25. Noyes AM, Dua K, Devadoss R, et al. Cardiac adipose tissue and its relationship to diabetes mellitus and cardiovascular disease. World $\mathrm{J}$ Diabetes. 2014:5:868-876

26. Nasrallah MP, Ziyadeh FN. Overview of the physiology and pathophysiology of leptin with special emphasis on its role in the kidney. Semin Nephrol. 2013;33:54-65

27. Ortega Moreno L, Lamacchia O, Copetti M, et al. Serum Adiponectin and Glomerular Filtration Rate in Patients with Type 2 Diabetes. PLoS One. 2015;10:e0140631.

28. Puurunen VP, Lepojärvi ES, Piira OP, et al. High plasma leptin levels are associated with impaired diastolic function in patients with coronary artery disease. Peptides. 2016;84:17-21.

29. Dey D, Nakazato R, Li D, et al. Epicardial and thoracic fat - Noninvasive measurement and clinical implications. Cardiovasc Diagn Ther. 2012;2:8593.

30. Rabkin SW, Campbell H. Comparison of reducing epicardial fat by exercise, diet or bariatric surgery weight loss strategies: a systematic review and meta-analysis. Obes Rev. 2015;16:406-415.

31. Benedek T, Oprincariu D, Rat $N$, et al. The Assessment of Epicardial Adipose Tissue in Acute Coronary Syndrome Patients. A Systematic Review. Journal of Cardiovascular Emergencies. 2017;3:18-29.

32. Cardoso AF, Furtado MS, Grindler J, et al. Epicardial Fat Thickness Correlates with P-wave Duration, Left Atrial Size and Decreased Left Ventricular Systolic Function in Morbid Obesity. Nutr Metab Cardiovasc Dis. 2017;27:473-582 